EXTENDED REPORT

\title{
Seven year changes in health status and priorities for improvement of health in patients with rheumatoid arthritis
}

\author{
T Heiberg, A Finset, T Uhlig, T K Kvien
}

Ann Rheum Dis 2005;64:191-195. doi: 10.1136/ard.2004.022699

See end of article for authors' affiliations

Correspondence to:

T Heiberg, MSN,

Department of

Administration, Ullevål

University Hospital,

$\mathrm{N}-0407$ Oslo, Norway:

turid.heiberg@ulleval.no

Accepted 9 May 2004
Objectives: To examine possible changes in priorities for improvement in health and health status from 1994 to 2001 within the setting of the Oslo Rheumatoid Arthritis (RA) Register, which provides representative data for the entire RA population in the county.

Methods: All living patients in the Oslo RA Register area received a postal questionnaire in 1994 and 2001, including the Arthritis Impact Measurement Scales 2 (AIMS2), Short Form-36, the modified Health Assessment Questionnaire, and pain and fatigue visual analogue scales (VAS). Priorities for improvement in health were examined through question 60 in AIMS2, where patients are asked to indicate three of 12 areas of health where they would most like to see improvement.

Results: The number of respondents aged 20-79 years in 1994/2001 was 932/830, with similar demographic characteristics $178.8 / 78.3 \%$ were female, mean age $60.6 / 60.8$, and disease duration $12.6 / 13.9$ years). Health status was improved in all dimensions, with statistical improvement for the physical dimension, global health and pain, from 1994 to 2001 . The profile of priorities remained mostly unchanged. Improvement in pain had the highest priority in both cohorts. Both symptom modifying and disease modifying drugs were more extensively used in 2001.

Conclusions: Health status had improved from 1994 to 2001, probably because of access to better and more aggressive treatments. Pain remained the area of highest priority for improvement among patients with RA-despite an improved level of pain in 2001.
O ver recent years, major changes have occurred in the provision of health care, and growing attention has been paid to the patient's perspective in health care and research. Improved management strategies with early and more aggressive treatment, ${ }^{1}$ together with access to more effective and specific drugs for patients with rheumatoid arthritis (RA), ${ }^{2-4}$ reflect important advances during recent years. Structural changes in health care during the same period also include reduction in the number of hospital beds and increased numbers of outpatient consultations.

Simultaneously, the patients' status and support for their impact on clinical decisions have been strengthenedreflected, for example, in legislation acts which have been passed that confirm patients' rights for information, consent, and contribution. ${ }^{5}$ It is recognised that patients want more information and expect to be more involved. ${ }^{67}$ Involvement has also been evident in research, as patients have been included as actual workshop participants at international meetings to consider the relevance and importance of outcomes and instruments from their perspective. Their opinions are also reflected in future research agendas. ${ }^{8-10}$

The discrepant views that healthcare providers and patients have on patients' health status, ${ }^{, 1}$ on the relevance of items and health construct questionnaires, ${ }^{12}$ and on the relative importance of different areas of health, ${ }^{13}$ make knowledge of patients' priorities essential. The research agenda developed at the patient perspective workshop during the consensus meeting on outcome research (OMERACT 6) included increased attention to patients' priorities. $^{8}$ Knowledge of patients' priorities should be of interest both at the individual level in clinical settings and at a population level for management strategies. Limited knowledge is available about the relation between health status and patients' priorities for improvement, or about how their priorities change with time.
Changes over time are typically studied by longitudinal observational studies of a patient cohort. ${ }^{14}$ The Oslo RA register provides data that are representative for the entire population in this geographic area. This setting makes possible a comparison of the changes in the burden of health over time in cross sectional cohorts. This ecological study aimed at examining possible changes from 1994 to 2001 in the priorities for improvement in areas of health and levels of self reported health for patients included in the Oslo RA Register.

\section{PATIENTS AND METHODS}

Patients with RA living in Oslo are included in the Oslo RA Register. ${ }^{15}$ The register is updated annually with information about new and deceased patients, including their residential addresses, being added. The completeness has been evaluated and is assumed to be $85 \% .^{15}{ }^{16}$ The number of enrolled cases has been fairly constant since the first data collection was performed in 1994. The current analyses focused on patients aged 20-79 years because the completeness of the register is only validated for this age group (1994 $\mathrm{n}=1316$; 2001 $\mathrm{n}=1413)$.

Mailed surveys to the patients on the register were sent in 1994 and again in 2001. ${ }^{17}$ The same core set of health status measures were included in both surveys, including the Arthritis Impact Measurement Scales 2 (AIMS2), ${ }^{18}$ the modified Health Assessment Questionnaire (MHAQ), ${ }^{19}$ the Short Form-36 (SF-36), ${ }^{20}$ and pain and fatigue visual analogue scales (VAS). AIMS2 is a multidimensional disease-specific instrument capturing information in 12 areas

Abbreviations: AIMS2, Arthritis Impact Measurement Scales 2; Cl, confidence interval; DMARDs, disease modifying antirheumatic drugs; MHAQ, modified Health Assessment Questionnaire; NSAIDs, nonsteroidal anti-inflammatory drugs; RA, rheumatoid arthritis; SF-36, Short Form-36; TNF, tumour necrosis factor; VAS, visual analogue scale 
Table 1 Comparisons of respondents and non-respondents in the 1994 and 2001 cohorts (mean $195 \% \mathrm{Cl}$ for continuous variables, percentage for counts)

\begin{tabular}{|c|c|c|c|c|c|c|}
\hline & \multicolumn{3}{|l|}{1994} & \multicolumn{3}{|l|}{2001} \\
\hline & $\begin{array}{l}\text { Respondents } \\
(\mathrm{n}=932 \text { ) }\end{array}$ & $\begin{array}{l}\text { Non-respondents } \\
(\mathrm{n}=384 \text { ) }\end{array}$ & p Value & $\begin{array}{l}\text { Respondents } \\
(\mathrm{n}=830 \text { ) }\end{array}$ & $\begin{array}{l}\text { Non-respondents } \\
(\mathrm{n}=583)\end{array}$ & p Value \\
\hline Age (years) & 60.6 (59.7 to 61.5$)$ & 62.4 (61.0 to 63.8$)$ & $0.03^{*}$ & 60.8 (59.9 to 61.7$)$ & $58.0(56.7$ to 59.2$)$ & $0.001^{*}$ \\
\hline Women (\%) & 78.8 & 81.5 & $0.02 \dagger$ & 78.3 & 76.2 & $0.38 \dagger$ \\
\hline Disease duration (years) & 12.6 (12.0 to 13.3$)$ & $14.2(13.0$ to 15.4$)$ & $0.26^{*}$ & $13.9(13.2$ to 14.6$)$ & $14.4(13.6,15.3)$ & $0.34^{*}$ \\
\hline
\end{tabular}

of health (mobility level, walking and bending, hand and finger function, arm function, self care tasks, household tasks, social activity, support from family and friends, pain, work, level of tension, mood) that can be aggregated into five major dimensions (physical, social interaction, pain, work, and effect). ${ }^{18}$ The score is from 0 to 10 ( 10 worst health). MHAQ is an eight item questionnaire measuring ability to perform daily activities ( scale $1-4,4$ worst health). ${ }^{19}$ SF-36 is a generic measure of eight health dimensions (physical functioning, physical role, bodily pain, general health, vitality, social functioning, emotional role, mental health) with scale from 0 to 100 ( 0 worst health). ${ }^{20}$ Utility scores were derived from the SF-36 according to the method of Brazier et al. ${ }^{22}$

Priorities for improvement in health were examined through question 60 in AIMS2 asking the patients to indicate three of 12 areas where they would most like to see improvement. ${ }^{182324}$

Current use of drugs was self reported on a checklist of the brand names of all antirheumatic drugs (both symptom

Table 2 Level of health status 1994 and 2001 (mean values $(95 \% \mathrm{Cl})$ )

\begin{tabular}{|c|c|c|}
\hline Health status & $1994(n=932)$ & $2001(n=830)$ \\
\hline \multicolumn{3}{|l|}{ Physical } \\
\hline MHAQ & 1.68 (1.64 to 1.72 ) & 1.58 (1.54 to 1.62$)$ \\
\hline AIMS2 & 2.77 (2.64 to 2.90$)$ & 2.25 (2.12 to 2.37$)$ \\
\hline SF-36 & 48.5 (46.8 to 50.2 ) & 52.3 (50.6 to 54.1$)$ \\
\hline \multicolumn{3}{|l|}{ Pain } \\
\hline VAS & $46.0(44.5$ to 47.6$)$ & 35.8 (34.2 to 37.5$)$ \\
\hline AIMS2 & 5.41 (5.24 to 5.58$)$ & $4.96(4.78$ to 5.14$)$ \\
\hline SF-36 & 41.2 (39.8 to 42.6$)$ & 43.5 (42.0 to 45.0$)$ \\
\hline \multicolumn{3}{|l|}{ Fatigue } \\
\hline VAS & 50.0 (48.2 to 51.8 ) & 46.9 (44.9 to 48.9 ) \\
\hline SF-36 & 39.8 (38.3 to 41.3 ) & 42.1 (40.6 to 43.6$)$ \\
\hline \multicolumn{3}{|l|}{ Global } \\
\hline VAS & 49.3 (47.8 to 51.0 ) & 39.8 (38.1 to 41.6 ) \\
\hline AlMS2 impact & 4.62 (4.44 to 4.80$)$ & $3.98(3.80$ to 4.15$)$ \\
\hline SF-36 & 42.1 (40.6 to 43.5$)$ & 45.1 (43.5 to 46.6$)$ \\
\hline \multicolumn{3}{|l|}{ Mental } \\
\hline AIMS2 & 3.28 (3.17 to 3.40$)$ & 3.30 (3.18 to 3.42 ) \\
\hline SF-36 & 68.2 (66.8 to 69.6$)$ & 70.6 (69.2 to 72.0$)$ \\
\hline \multicolumn{3}{|l|}{ Social } \\
\hline AIMS2 & 4.28 (4.17 to 4.39$)$ & 4.05 (3.94 to 4.16$)$ \\
\hline SF-36 & 64.3 (62.4 to 66.2 ) & 66.8 (64.9 to 68.7 ) \\
\hline \multicolumn{3}{|l|}{ Role } \\
\hline SF-36 physical & 27.8 (25.5 to 30.2 ) & 30.3 (27.8 to 32.9 ) \\
\hline SF-36 mental & $51.9(49.2$ to 54.6$)$ & 56.1 (53.2 to 59.0$)$ \\
\hline \multicolumn{3}{|l|}{ Utility } \\
\hline SF-6D & $0.616(0.067$ to 0.625$)$ & $0.639(0.629$ to 0.649$)$ \\
\hline
\end{tabular}

Significant improvement (non-overlapping confidence intervals) is indicated in italics. modifying and disease modifying) that were available at the time of the study.

Descriptive statistics were applied. Continuous variables are presented as mean values, categorical values as counts or proportions, all with their $95 \%$ confidence intervals (CI). At a conservative estimate we assumed that an important/ significant change (cohort effect) had occurred if the 95\% CI intervals of a measure in 1994 and 2001 did not overlap.

\section{RESULTS}

The important demographic and disease variables of the respondents in the examined cohorts in $1994(\mathrm{n}=932)$ and $2001(\mathrm{n}=830)$ did not differ (table 1$)$. About half of the patients $(n=475)$ were represented in both cohorts.

Health status was statistically or numerically improved across all dimensions of health from 1994 to 2001 (table 2). The most consistent and pronounced improvement across instruments was seen for the physical dimension and global health measures (table 2), but statistically significant improvement was also observed for two out of the three pain measures. The utility score improved by 0.023 (table 2 ).

Table 3 shows levels of health status in 1994 and 2001 for the 12 areas of health in AIMS2, and reported priorities for improvement within the same areas. In general, levels of health were improved, especially within the physical dimension and pain. Distribution of priorities remained unchanged, though with a smaller proportion of patients reporting priorities for improvement within arm function and self care in 2001 compared with 1994. Pain was the area of health where most patients wanted to see improvement, both in 1994 and 2001, despite a major improvement in pain intensity in 2001.

More than half of the patients $(51.0 \%)$ used disease modifying antirheumatic drugs (DMARDs) or tumour necrosis factor (TNF) blocking agents in 2001 compared with $36.5 \%$ users of DMARDs in 1994 (table 4). Fewer patients received traditional non-steroidal anti-inflammatory drugs (NSAIDs) in 2001 (table 4), but more patients received either traditional NSAIDs or COX-2 selective NSAIDs (coxibs) (1994: $45.2 \%$ (95\% CI 42.0 to 48.4 ); 2001 : $52.3 \%$ (48.9 to 55.7)). In both cohorts, patients with priority for improvement in pain used more drugs than patients without this priority (table 4). However, about one third of the patients in both cohorts with priority for improvement in pain did not report use of any relevant symptom modifying drugs (data not shown).

To examine the robustness of the data for improved health, we did several subgroup analyses. A similar trend in improvement from 1994 to 2001 was seen in patients with short ( $\leqslant 5$ years) and long ( $>5$ years) disease duration, as well as in patients with less and more education. Patients responding at both times $(\mathrm{n}=475)$ had as expected worse health in 2001 than in 1994 owing to the 7 year increase in age and disease duration. Patients responding only in 1994 had considerably worse health than patients responding only in 2001. Of the 457 responding in 1994, but not responding in 
Table 3 Priorities for improvement in 12 areas of health (AIMS2) and reported health status in the corresponding areas (percentages for counts, mean values for continuous variables $(95 \% \mathrm{Cl})$ )

\begin{tabular}{|c|c|c|c|c|c|c|c|c|}
\hline & \multicolumn{4}{|l|}{1994} & \multicolumn{4}{|l|}{2001} \\
\hline & \multicolumn{2}{|c|}{ Priority } & \multicolumn{2}{|c|}{ Reported health status } & \multicolumn{2}{|c|}{ Priority } & \multicolumn{2}{|c|}{ Reported health status } \\
\hline & (\%) & $\mathrm{Cl}$ & Mean & $\mathrm{Cl}$ & $\%$ & $\mathrm{Cl}$ & Mean & $\mathrm{Cl}$ \\
\hline Mobility & 23.5 & 20.8 to 26.2 & 2.48 & 2.31 to 2.65 & 19.8 & 17.1 to 22.5 & 1.91 & 1.76 to 2.07 \\
\hline Walking/bending & 33.2 & 30.2 to 36.2 & 4.99 & 4.81 to 5.16 & 32.2 & 29.0 to 35.4 & 4.54 & 4.35 to 4.72 \\
\hline Hand and finger & 45.0 & 41.8 to 48.2 & 3.62 & 3.44 to 3.80 & 41.6 & 38.1 to 44.9 & 3.05 & 2.88 to 3.22 \\
\hline Arm function & 18.2 & 15.7 to 20.7 & 2.28 & 2.12 to 2.44 & 13.4 & 11.1 to 15.7 & 1.78 & 1.63 to 1.93 \\
\hline Self care & 11.5 & 9.5 to 13.5 & 1.22 & 1.09 to 1.35 & 6.9 & 5.2 to 8.6 & 0.69 & 0.59 to 0.80 \\
\hline Housework & 25.1 & 22.3 to 27.9 & 2.04 & 1.88 to 2.21 & 28.7 & 25.6 to 31.8 & 1.52 & 1.38 to 1.66 \\
\hline Social function & 13.0 & 10.8 to 15.2 & 5.72 & 5.62 to 5.82 & 9.4 & 7.4 to 11.4 & 5.38 & 5.28 to 5.48 \\
\hline Social support & 4.9 & 3.5 to 6.3 & 2.85 & 2.69 to 3.01 & 5.8 & 4.2 to 7.4 & 2.75 & 2.59 to 2.91 \\
\hline Pain & 69.3 & 66.3 to 72.3 & 5.41 & 5.24 to 5.58 & 68.1 & 64.9 to 71.3 & 4.96 & 4.78 to 5.14 \\
\hline Work & 9.4 & 7.5 to 11.3 & 2.75 & 2.50 to 3.01 & 12.0 & 9.7 to 14.1 & 2.30 & 2.04 to 2.55 \\
\hline Tension & 9.1 & 7.3 to 10.9 & 3.96 & 3.82 to 4.09 & 12.9 & 10.6 to 15.2 & 3.85 & 3.71 to 3.98 \\
\hline Mood & 17.4 & 15.0 to 19.8 & 2.91 & 2.79 to 3.03 & 16.6 & 14.1 to 19.1 & 2.76 & 2.63 to 2.88 \\
\hline
\end{tabular}

2001, 195 had died, 66 had moved out of Oslo (withdrawn from the register), and 196 were classified as nonrespondents.

\section{DISCUSSION}

Healthcare providers frequently ask patients, "How are you?", collecting information about sleep, mobility, abdominal discomfort, musculoskeletal pain, etc. The scientific counterpart is health status measures, asking patients to report on levels of health. The question, "What is important to you?", differs in approach, and opens an opportunity for the patient to pursue her or his goals and to enter a discussion enabling shared decision-making. The corresponding research topic, asking for patients' priorities for improvement, is less frequently explored in clinical research, as was emphasised in the research agenda that emerged after the workshop on patient perspective in outcome research during OMERACT 6 in 2002. ${ }^{8}$

This paper focuses on change both in patients' self reported health status and their priorities for improvement in the same areas of health during a period of time in which major changes in treatment and healthcare values and structure have occurred. ${ }^{1-4}$ Health status was found to be improved across all dimensions of health and also across different instruments within the same dimensions (table 2). This observation echoes what experienced clinicians often saynamely, that the overall health of patients with RA has improved over recent years. This evidence for an improvement in health of patients with RA during recent years is relevant, taking into account the considerable costs for society and the individual suffering that are consequences of this disease. ${ }^{25}{ }^{26}$ Societal relevance of this improvement is reflected by a favourable change in self care as well as the utility score. The 0.023 change in utility means that 100 patients together have gained 2.3 quality adjusted life years. Further, an MHAQ improvement of 0.10 corresponds to an average impact of 3 years disease course on the disability score. ${ }^{27}$

We found an increase in the use of drugs, both symptom modifying and disease modifying, in 2001 compared with 1994. Thus, more aggressive use of disease modifying drugs may be a possible explanation ${ }^{1}$ as well as access to new biological treatments ${ }^{2}$ and symptom modifying drugs with improved gastrointestinal safety. ${ }^{3}{ }^{4}$ Levels of self efficacy were unchanged (data not shown), suggesting that changes in self management skills did not have any major role. However, epidemiological data over recent years have also indicated a decreased overall incidence of $\mathrm{RA}^{28}{ }^{29}$ and a shift in the incidence from younger to older people, ${ }^{3031}$ at least in women. Thus, our data may also reflect a natural development of the disease towards a lower incidence ${ }^{32}$ and a milder disease, as was suggested already more than 20 years ago. ${ }^{33}$ Another possible explanation is that it may reflect an overall improvement in population health, but repeated surveys with the SF-36 in the Norwegian population have not been performed. Sequential cross sectional data from other representative disease cohorts are also not available.

Our department was responsible for the rheumatological care of most of the patients in the two cohorts. One could ask whether the improvement in health status was related to structural changes in health care from 1994 to 2001. Even though the number of beds and the duration of hospital stays

Table 4 Reported use of drugs in 1994 and 2001 (percentages (95\% Cl)) and comparisons between patients with and without priority for improvement in pain

\begin{tabular}{|c|c|c|c|c|c|c|c|c|}
\hline & \multicolumn{2}{|l|}{$\%$ Users } & \multicolumn{6}{|c|}{ Pain improvement } \\
\hline & \multirow{2}{*}{$\begin{array}{l}1994 \\
(n=932)\end{array}$} & \multirow[b]{2}{*}{$\begin{array}{l}2001 \\
(n=830)\end{array}$} & \multicolumn{3}{|l|}{1994} & \multicolumn{3}{|l|}{2001} \\
\hline & & & $\begin{array}{l}\text { With } \\
\text { priority } \\
(n=646)\end{array}$ & $\begin{array}{l}\text { Without } \\
\text { priority } \\
(\mathrm{n}=286 \text { ) }\end{array}$ & p Value & $\begin{array}{l}\text { With } \\
\text { priority } \\
(n=565)\end{array}$ & $\begin{array}{l}\text { Without } \\
\text { priority } \\
(n=265)\end{array}$ & p Value \\
\hline NSAIDs & 45.2 (42.0 to 48.4$)$ & 37.1 (33.8 to 40.4$)$ & 49.1 & 36.4 & $<0.001$ & 38.9 & 33.2 & 0.11 \\
\hline Coxibs & & $15.2(12.8$ to 17.6$)$ & & & & 17.5 & 10.2 & 0.002 \\
\hline Analgesics & 25.1 (22.3 to 27.9$)$ & 26.9 (23.9 to 29.9 ) & 26.3 & 22.4 & 0.20 & 29.6 & 21.1 & 0.01 \\
\hline Corticosteroids & 40.8 (37.6 to 44.0 ) & 42.8 (39.4 to 46.2$)$ & 42.0 & 38.1 & 0.27 & 44.8 & 38.5 & 0.10 \\
\hline DMARDs & 36.5 (33.4 to 39.6$)$ & 47.8 (44.4 to 51.2 ) & 37.8 & 33.6 & 0.22 & 50.3 & 42.6 & 0.04 \\
\hline TNF blocking agents & & $3.1(-0.1$ to 6.9$)$ & & & & 3.0 & 3.4 & 0.59 \\
\hline
\end{tabular}


have decreased, similar numbers of patients were admitted to hospital, and waiting lists and surgical procedures were largely similar in our department in 1994 and 2001. Outpatient consultations increased during this period, with a potentially better access to early and aggressive treatment with new drugs. ${ }^{1}$ However, the distributions of disease duration were similar in 1994 and in 2001, suggesting that the referral pattern had not changed in the direction of more early referrals.

Previous findings have indicated that asking patients for their priorities for improvement in health, provides information that is complementary to health status measures. ${ }^{23}$ The present findings seem to support this observation, as the improvement in health status was not consistently accompanied by a similar change in priority for improvement, except for arm function and self care.

Different explanations may exist for the lack of a clear relationship between health status and reported priority. The burden of disease may be so heavy in some areas ${ }^{25} 26$ that an improvement does not necessarily alter a patient's priorities for improvement. Pain intensity may be improved, but pain may still have sufficient impact on the quality of life to remain the top priority for improvement. This observation is in agreement with previous studies, emphasising that pain is a major concern for patients. ${ }^{34-36}$

The perceived importance of health areas may also be influenced by social status and access to social welfare, ${ }^{37} 38$ patient values, ${ }^{39}$ attitudes, ${ }^{40}$ and self efficacy.$^{41}$ Possibly, the lack of relevant instruments that would allow a study of patients' priorities is also one plausible reason. In this study priorities were measured as the proportion of patients reporting three of 12 areas of health where they would like to see improvement-that is, as a categorical variable, whereas health status was measured on scales (continuous variables).

We found that patients with priority for improvement in pain used more symptom modifying drugs than patients without this priority (table 4), but there were still many patients not receiving relevant drug treatment. Reasons for this may be related to fear of side effects, lack of information, ${ }^{42}$ non-compliance due to low patient participation in clinical decision-making ${ }^{43}{ }^{44}$ or social patient characteristics. $^{45}$

The existence of the Oslo RA Register was an opportunity to compare two population based cohorts examined 7 years apart and assumed to be representative of the entire RA population in the area. The latter assumption is based on a previous study showing that the register is $85 \%$ complete $^{16}$ and that the number of patients in the register has remained fairly constant after this validation of the completeness. Both cohorts had similar demographics, which strengthens the probability of the truth of this assumption. The two cohorts were exposed to the same instruments. This combination of generic and disease-specific instruments allowed us to examine whether findings were consistent across different approaches. As an alternative approach we performed traditional longitudinal analyses only on patients with complete data at both times $(\mathrm{n}=475),{ }^{46}$ showing that patients in accordance with increased age and disease duration developed worse physical functioning. The mean 7 year change in MHAQ in the paired data was 0.13 , which was somewhat less than expected from the average annual increase in disability score of 0.03 , found in the follow up studies in Wichita (that is, accumulated to 0.21 during 7 years).$^{27}$

The respondent rate was reduced over the 7 years. Another study limitation was the differences in characteristics of nonrespondents (table 1). In 1994, non-respondents were older, as commonly seen in surveys, but they were somewhat younger in $2001 .{ }^{47}$ We have earlier suggested that priorities differ somewhat with age, with higher priority for improvement in physical functioning for the elderly, and in pain, work, and mental conditions for the younger patients. ${ }^{23}$

Question 60 in AIMS2 has some limitations as half of the items concern physical function, and items like sleep or fatigue, highlighted as important by patients, ${ }^{9}$ are not included. Another limitation is that the patients were not offered the opportunity to rank the relative importance of the three prioritised areas. Assessment of patients' priorities deserves to be increasingly examined. Qualitative approaches may be suited to investigation of priorities and are in increasing use, ${ }^{6849}$ but there still is a need for additional research in this area. For a quantitative approach, the development of feasible and valid instruments is needed. ${ }^{50}$ Such new instruments should focus on outcomes that are important to the patients. ${ }^{4951}$

In summary, this study suggest that health status in RA has improved from 1994 to 2001. This improvement may be related to improved treatment during this period. The profile of patients' priorities for improvement remained mostly unchanged. Present and previous data indicate more focus on developing instruments to elicit patients' priorities for improvement in health. Research and the daily clinic should both aim at finding answers to the two basic clinical questions to patients: "How are you?" and "What is important to you?". Without the impact of patients' priorities on clinical decisions, we may be left with good intentions and bad outcomes.

\section{ACKNOWLEDGEMENTS}

This study was supported by Jan A Pahle's Research Legacy. The maintenance of the register has been supported by the Norwegian Rheumatism Association, the Norwegian Women Public Health Association, Trygve Gythfeldt and Wife's Legacy, Grethe Harbitz's Legacy, and Marie and Else Mustad's Legacy.

We thank Petter Mowinckel for statistical advice and analyses.

\section{Authors' affiliations}

T Heiberg, Department of Administration, Ulleval University Hospital, Oslo, Norway

A Finset, T Uhlig, National Resource Centre for Rehabilitation in Rheumatology, Diakonhjemmet Hospital, Oslo, Norway

T K Kvien, Department of Rheumatology, Diakonhjemmet Hospital, Oslo, Norway

\section{REFERENCES}

1 Emery P, Breedveld FC, Dougados M, Kalden JR, Schiff MH, Smolen JS. Early referral recommendation for newly diagnosed rheumatoid arthritis: evidence based development of a clinical guide. Ann Rheum Dis 2002;61:290-7.

2 Furst DE, Breedveld FC, Kalden JR, Smolen JS, Burmester GR, Dougados M, et al. Updated consensus statement on biological agents for the treatment of rheumatoid arthritis and other immune mediated inflammatory diseases (May 2003). Ann Rheum Dis 2003;62(uppl 2):ii2-9.

3 Bombardier C, Laine L, Reicin A, Shapiro D, Burgos-Vargas R, Davis B, et al. Comparison of upper gastrointestinal toxicity of rofecoxib and naproxen in patients with rheumatoid arthritis. VIGOR Study Group. N Engl J Med 2000;343:1520-8.

4 Hawkey CJ. NSAID toxicity: where are we and how do we go forward? $J$ Rheumatol 2002;29:650-2.

5 Norwegian Ministry of Health and Social Affairs (Sosial- og Helsedepartementef). Law on Patients' Rights of $2^{\text {nd }}$ July 1999 No 63

6 Ryan S. Living with rheumatoid arthritis: a phenomenological exploration. Nurs Stand 1996;10:45-8.

7 Brekke M, Hjortdahl P, Kvien TK. Involvement and satisfaction: a Norwegian study of health care among 1,024 patients with rheumatoid arthritis and 1,509 patients with chronic noninflammatory musculoskeletal pain. Arthritis Rheum 2001;45:8-15.

8 Kirwan J, Heiberg T, Hewlett S, Hughes R, Kvien T, Ahlmen M, et al. Outcomes from the Patient Perspective Workshop at OMERACT 6. J Rheumatol 2003;30:868-72.

9 Quest E, Aanerud GJ, Kaarud S, Collins S, Leong A, Smedeby B, et al. Patients' perspective. J Rheumatol 2003;30:884-5

10 Wells G, Anderson J, Boers M, Felson D, Heiberg T, Hewlett S, et al. MCID/ Low Disease Activity State Workshop: Summary, Recommendations, and Research Agenda. J Rheumatol 2003;30:1115-18. 
11 Kwoh CK, O'Connor GT, Regan-Smith MG, Olmstead EM, Brown LA, Burnett JB, et al. Concordance between clinician and patient assessment of physical and mental health status. J Rheumatol 1992;19:1031-7.

12 Hewlett S, Smith AP, Kirwan JR. Values for function in rheumatoid arthritis: patients, professionals, and public. Ann Rheum Dis 2001;60:928-33.

13 Rothwell PM, McDowell Z, Wong CK, Dorman PJ. Doctors and patients don't agree: cross sectional study of patients' and doctors' perceptions and assessments of disability in multiple sclerosis. BMJ 1997;314:1580-3.

14 Wolfe F, Lassere M, van der HD, Stucki G, Suarez-Almazor M, Pincus T, et al. Preliminary core set of domains and reporting requirements for longitudinal observational studies in rheumatology. J Rheumatol 1999;26:484-9.

15 Kvien TK, Glennas A, Knudsrod OG, Smedstad LM, Mowinckel P, Forre O. The prevalence and severity of rheumatoid arthritis in Oslo. Results from a county register and a population survey. Scand J Rheumatol 1997;26:412-18.

16 Kvien TK, Uhlig T. The Oslo experience with arthritis registries. Clin Exp Rheumatol 2003;21(suppl 31):S118-22.

17 Kvien TK, Uhlig T. The population based studies in rheumatoid arthritis. A method of longterm followup studies. J Rheumatol Suppl 2004;69:35-40.

18 Meenan RF, Mason JH, Anderson JJ, Guccione AA, Kazis LE. AIMS2. The content and properties of a revised and expanded Arthritis Impact Measurement Scales Health Status Questionnaire. Arthritis Rheum 1992;35:1-10.

19 Pincus T, Summey JA, Soraci SA Jr, Wallston KA, Hummon NP. Assessment of patient satisfaction in activities of daily living using a modified Stanford Health Assessment Questionnaire. Arthritis Rheum 1983;26:1346-53.

20 Kvien TK, Kaasa S, Smedstad LM. Performance of the Norwegian SF-36 Health Survey in patients with rheumatoid arthritis. II. A comparison of the SF36 with disease-specific measures. J Clin Epidemiol 1998;51:1077-86.

21 Ware JE Jr, Sherbourne CD. The MOS 36-item short-form health survey (SF36). I. Conceptual framework and item selection. Med Care 1992;30:473-83.

22 Brazier J, Roberts J, Deverill M. The estimation of a preference-based measure of health from the SF-36. J Health Econ 2002;21:271-92.

23 Heiberg T, Kvien TK. Preferences for improved health examined in 1,024 patients with rheumatoid arthritis: pain has highest priority. Arthritis Rheum 2002:47:391-7.

24 Archenholtz B, Bjelle A. Reliability, validity, and sensitivity of a Swedish version of the revised and expanded Arthritis Impact Measurement Scales (AIMS2). J Rheumatol 1997;24:1370-7.

25 Woolf AD. Bone and joint futures. London: BMJ Books, 2002

26 Report of a WHO Scientific Group. The burden of musculoskeletal conditions at the start of the new millennium. WHO Technical Report Series, 2003:919.

27 Wolfe F. A reappraisal of HAQ disability in rheumatoid arthritis. Arthritis Rheum 2000;43:2751-61.

28 Shichikawa K, Inoue K, Hirota S, Maeda A, Ota H, Kimura M, et al. Changes in the incidence and prevalence of rheumatoid arthritis in Kamitonda, Wakayama, Japan, 1965-1996. Ann Rheum Dis 1999:58:751-6.

29 Doran MF, Pond GR, Crowson CS, O'Fallon WM, Gabriel SE. Trends in incidence and mortality in rheumatoid arthritis in Rochester, Minnesota, over a forty-year period. Arthritis Rheum 2002;46:625-31.
30 Imanaka T, Shichikawa K, Inoue K, Shimaoka Y, Takenaka Y, Wakitani S. Increase in age at onset of rheumatoid arthritis in Japan over a 30 year period. Ann Rheum Dis 1997;56:313-16.

31 Kaipiainen-Seppanen $\mathrm{O}$, Aho $\mathrm{K}$, Isomaki $\mathrm{H}$, Laakso M. Shift in the incidence of rheumatoid arthritis toward elderly patients in Finland during 1975-1990. Clin Exp Rheumatol 1996; 14:537-42.

32 Silman AJ. The changing face of rheumatoid arthritis: why the decline in incidence? Arthritis Rheum 2002;46:579-81.

33 Silman AJ. Are there secular trends in the occurrence and severity of rheumatoid arthritis? Scand J Rheumatol 1989;(suppl 79):25-30.

34 Minnock P, FitzGerald O, Bresnihan B. Women with established rheumatoid arthritis perceive pain as the predominant impairment of health status. Rheumatology (Oxford) 2003;42:995-1000.

35 Jansen LA. Deliberative decision making and the treatment of pain. J Palliat Med 2001;4:23-30.

36 Lang JD Jr. Pain. A prelude. Crit Care Clin 1999;15:1-16.

37 Brekke M, Hjortdahl P, Kvien TK. Severity of musculoskeletal pain: relations to socioeconomic inequality. Soc Sci Med 2002;54:221-8.

38 Dadoniene J, Uhlig T, Stropuviene S, Venalis A, Boonen A, Kvien TK. Disease activity and health status in rheumatoid arthritis: a case-control comparison between Norway and Lithuania. Ann Rheum Dis 2003:62:231-5.

39 DeVellis RF, Patterson CC, Blalock SJ, Renner BR, DeVellis BM. Do people with rheumatoid arthritis develop illness-related schemas? Arthritis Care Res 1997; 10:78-88.

40 Myllykangas M, Ryynanen OP, Lammintakanen J, Isomaki VP, Kinnunen J, Halonen P. Clinical management and prioritization criteria. Finnish experiences. J Health Organ Manag 2003;17:338-48.

41 Brekke M, Hjortdahl P, Kvien TK. Self-efficacy and health status in rheumatoid arthritis: a two-year longitudinal observational study. Rheumatology (Oxford) $2001 ; 40: 387-92$

42 Kanning $M$. Why I would want to use complementary and alternative therapy: a patient's perspective. Rheum Dis Clin North Am 1999;25:823-31.

43 Hausman A. Taking your medicine: relational steps to improving patient compliance. Health Mark Q 2001;19:49-71.

44 Guadagnoli E, Ward P. Patient participation in decision-making. Soc Sci Med 1998;47:329-39.

45 Langer N. Culturally competent professionals in therapeutic alliances enhance patient compliance. J Health Care Poor Underserved 1999;10:19-26.

46 Heiberg T, Finset A, Uhlig T, Kvien TK. Changes over 7 years in patients' priorities for improvement in health: A study of patients with rheumatoid arthritis (RA) from a population based register (abstract). Arthritis Rheum 2002;46(suppl):401.

47 Wolfe F, Pincus T. Listening to the patient: a practical guide to self-report questionnaires in clinical care. Arthritis Rheum 1999;42:1797-808

48 Edwards J, Mulherin D, Ryan S, Jester R. The experience of patients with rheumatoid arthritis admitted to hospital. Arthritis Rheum 2001:45:1-7.

49 Carr A, Hewlett S, Hughes R, Mitchell H, Ryan S, Carr M, et al. Rheumatology outcomes: the patient's perspective. J Rheumatol 2003;30:880-3

50 Liang MH, Lew RA, Stucki G, Fortin PR, Daltroy L. Measuring clinically important changes with patient-oriented questionnaires. Med Care 2002;40(suppl):II45-51

51 Saag KG. OMERACT 6 brings new perspectives to rheumatology measurement research. J Rheumatol 2003;30:639-41. 